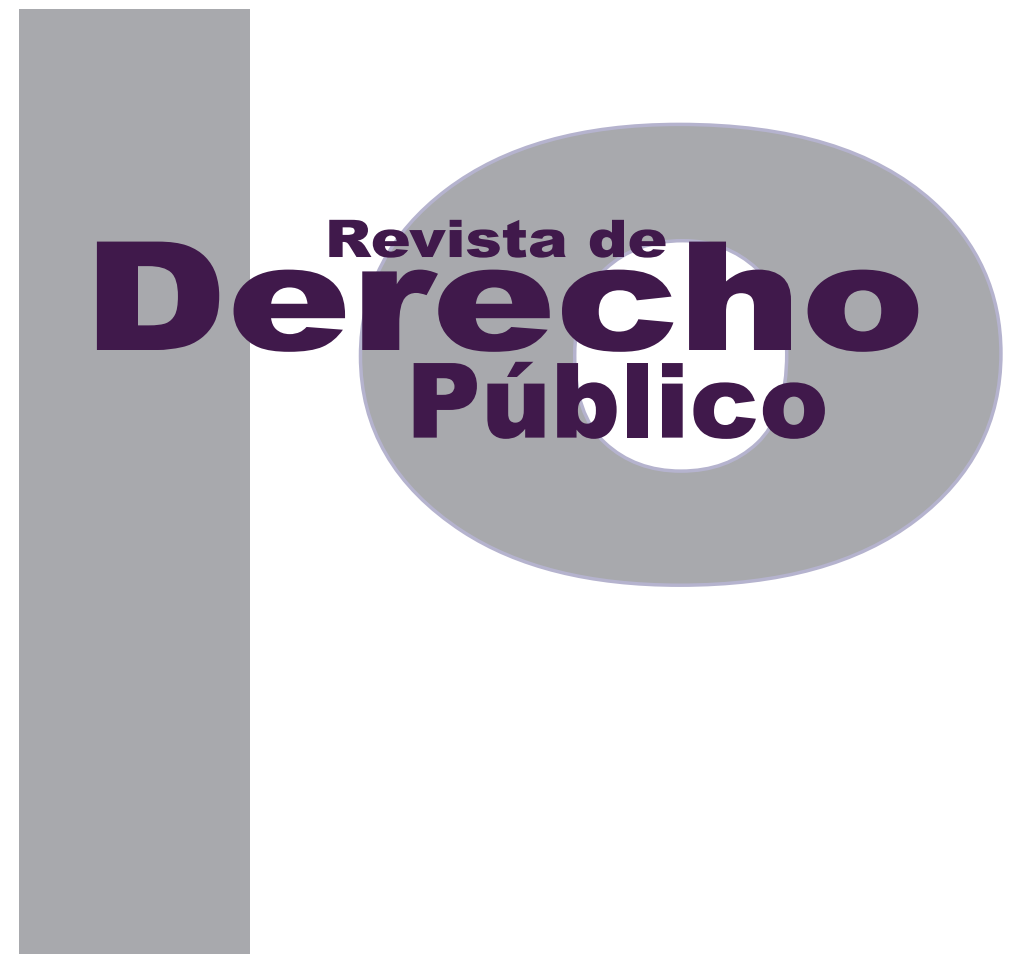

\title{
MACKINNON EN EL PALACIO DE JUSTICIA: UN ANÁLISIS RADICAL DE SENTENCIAS DE LA CORTE CONSTITUCIONAL SOBRE SEXUALIDAD
}

\author{
SALOMÉ GóMEZ UPEGUI \\ Artículo de reflexión \\ DOI: http://dx.doi.org/10.15425/redepub.35.2015.14 \\ Universidad de los Andes \\ Facultad de Derecho \\ Rev. derecho publico No.35 \\ julio - diciembre de 2015. ISSN 1909-7778
}




\section{Mackinnon en el palacio de justicia: un análisis radical de sentencias de la corte constitucional sobre sexualidad}

Resumen

Este artículo es una reflexión sobre cómo la teoría del feminismo radical de Catharine Mackinnon puede ser una herramienta metodológica para analizar lo cotidiano. Específicamente, el texto busca dar luz acerca de aspectos relevantes de género que no habían sido discutidos antes en sentencias de la Corte Constitucional colombiana sobre sexualidad femenina. Para lograr esto se propone una concepción simplificada de la teoría de MacKinnon que luego se utiliza para analizar casos sobre medios y publicidad, educación sexual y mujeres que visitan las cárceles de hombres. En la conclusión la autora plantea lo normalizado que está en la sociedad expropiar a la mujer de su sexualidad.

Palabras clave: derecho constitucional, feminismo, sexualidad, jurisprudencia.

\section{Mackinnon in the courthouse: a radical analysis of constitutional court sentences on sexuality}

\section{Abstract}

This article is a reflection on how Catharine MacKinnon's radical feminist theory can be used as a methodological tool to analyze every day topics. Specifically, this text sheds light on relevant gender issues that had not been discussed earlier in Colombian Constitutional Court decisions on female sexuality. In order to do this, the article proposes a simplified conception of Mackinnon's theory that is then used to analyze cases on media and advertising, sexual education and women who visit men's prisons. In conclusion the author argues that the expropriation of women's sexuality is normalized in society.

Keywords: constitutional law, feminism, sexuality, jurisprudence.

\section{Mackinnon no palácio de justiça: uma análise radical de sentenças da corte constitucional sobre sexualidade}

\section{Resumo}

Este artigo é uma reflexão sobre como a teoria do feminismo radical de Catharine MacKinnon pode ser uma ferramenta metodológica para analisar o cotidiano. Especificamente, o texto busca dar luz acerca de aspectos relevantes de gênero que não tinham sido discutidos antes em sentenças da Corte Constitucional colombiana sobre a sexualidade feminina. Para conseguir isto, propõe-se uma concepção simplificada da teoria de MacKinnon que depois é utilizada para analisar casos sobre meios e publicidade, educação sexual e mulheres que visitam prisões masculinas. Na conclusão a autora expõe o quão normalizado que está na sociedade expropriar a mulher de sua sexualidade.

Palavras-chave: direito constitucional, feminismo, sexualidade, jurisprudência. 


\title{
Mackinnon en el palacio de justicia: un análisis radical de sentencias de la corte constitucional sobre sexualidad*
}

\author{
Salomé Gómez Upegui ${ }^{* *}$
}

\section{SUMARIO}

Introducción - Metodología - I. EL ARGUMENTO DE CATHARINE A. MACKINNON - A. La expropiación de la sexualidad femenina - B. El vehículo de la expropiación de la sexualidad femenina - C. La subordinación de la mujer - D. ¿Qué pasa cuando esto le sucede a los hombres? - II. LA SEXUALIDAD FEMENINA EN LA JURISPRUDENCIA DE LA CORTE CONSTITUCIONAL COLOMBIANA - A. Medios y publicidad - B. Educación sexual - C. Las mujeres que visitan cárceles de hombres - III. CONCLUSIONES - Referencias.

Cómo citar este artículo: Gómez Upegui, S. (Diciembre, 2015). MacKinnon en el Palacio de Justicia: un análisis radical de sentencias de la Corte Constitucional sobre sexualidad. Revista de Derecho Público, 35. Universidad de los Andes (Colombia).

** Abogada de la Universidad de los Andes. Correo: salomegomezu@gmail.com.

Agradezco a Isabel Cristina Jaramillo y a Helena Alviar su apoyo en la realización de este artículo. 
Introducción

Vivimos en una sociedad en la que nos aseguran que los hombres y las mujeres somos iguales. En la que no vemos que estamos lejos de serlo. ${ }^{1}$ En la que la promesa constitucional por la igualdad es, en demasiados aspectos, vacía. Para reconocer la posición inferior del sexo femenino en la sociedad, ${ }^{2}$ el primer paso que debemos dar es reconocer que la falta de poder de la mujer es algo internalizado y externamente impuesto. ${ }^{3}$ El feminismo radical permite entender esto más a fondo no solo desde una perspectiva teórica sino en casos concretos. En este escrito busco precisamente esto: mostrar cómo el feminismo radical nos da herramientas para hablar de lo cotidiano.

La feminista norteamericana Catharine A. MacKinnon es reconocida por sus ideas frente a la desigualdad entre hombres y mujeres y la relación directa de esta con la concepción sexualizada de la mujer. Su teoría ha sido muy debatida por ser considerada extremista y exagerada. Aun así, una lectura detallada de la obra de MacKinnon permite encontrar herramientas

1 En su texto Feminism unmodified, MacKinnon afirma que existe una creencia generalizada en el mundo de que los hombres y las mujeres somos básicamente iguales (1987, p. 168)

2 Si bien existe una diferencia clara entre los conceptos de sexo y género, pues el primero se refiere a las características biológicas de hombres y mujeres, y el segundo a lo socialmente construido e impuesto a partir de esas diferencias biológicas, MacKinnon (1989) parte de la base según la cual la desigualdad de la mujer es atribuible a su condición biológica de mujer, esto es, a su sexo. En esta medida, a través del texto utilizaré el concepto de sexo por oposición al de género.

3 Para MacKinnon es precisamente por esto que, por ejemplo, la feminidad es identidad para la mujer y deseabilidad para los hombres (citada en García, Jaramillo y Restrepo, 2006, p. 168). útiles para realmente valorar los escenarios de subordinación de la mujer, que como lo sostendré, son más amplios de lo que muchos asumirían. Su tesis presenta el feminismo en su forma más pura pues, como ella misma lo sostiene, sus ideas no necesitan refugio en alguna construcción política o social masculina para cobrar sentido. ${ }^{4}$ Con todo esto en mente, el feminismo radical que predica Mackinnon es el fundamento de lo que expresaré en este texto.

Mi concepción del argumento de MacKinnon está fundamentalmente dividida en tres ideas. Primera, la mujer ha sido sometida por el hombre a través de la expropiación de lo que le es más suyo, la sexualidad. Segunda, la forma en que esta expropiación se ha hecho ha sido a través de las acciones, que como explicaré, se confunden constantemente con meras expresiones. Y finalmente, la consecuencia central de esto ha sido el silenciamiento de las mujeres como grupo social, la subordinación femenina. ${ }^{5}$ Una aclaración que propone Mackinnon a su tesis y que analizaré, es que la expropiación de la sexualidad masculina no puede equipararse con el caso de las mujeres, pues los supuestos en que esto sucede no definen a los hombres como grupo social. En fin, la teoría de Mackin-

4 Mackinnon sostiene que si bien se ha considerado que el feminismo, en gran medida, contiene tendencias de feminismo liberal, feminismo radical y feminismo social, aplicadas a las mujeres el feminismo social a menudo equivale al marxismo y el feminismo liberal al liberalismo, mientras que el feminismo radical es el verdadero feminismo (citada en García et al., 2006, p. 197).

5 Las mujeres se deben concebir como un grupo social en la medida en que se convierten implícitamente en un grupo de interés dentro del pluralismo, con problemas específicos de movilización y representación, presencia y voz, que soporta pérdidas y ganancias incrementales (MacKinnon, 1989, p. 284). 
non es, en últimas, sobre las relaciones de poder y la falta de equidad. Sobre cómo el poder masculino construye un mundo desde su punto de vista, para luego llamarlo la realidad. ${ }^{6}$

Habiendo explicado este argumento, el propósito del artículo es utilizarlo como una herramienta de análisis jurisprudencial en sentencias de la Corte Constitucional colombiana. Específicamente, las sentencias elegidas abordan los temas de cuerpo y sexualidad femenina; con la presentación de estas propondré que más allá de las discusiones elevadas por la Corte estos casos son, en efecto, de expropiación de la sexualidad femenina y discriminación de la mujer. Así, este será un ejercicio para demostrar que Mackinnon puede iluminar muchos aspectos determinantes para la realidad actual de las mujeres y permitirnos ver lo que la Corte en sus sentencias no muestra. A su vez, este análisis llevará las ideas de la autora a conversar con aspectos fácticos que ella misma no ha evaluado en detalle antes, como son los casos de medios y publicidad, educación sexual y mujeres que visitan cárceles de hombres.

Finalmente, además de querer presentar los efectos de utilizar las ideas de MacKinnon como una herramienta metodológica, tengo un fin secundario: elevar conciencia, por lo menos en lo que concierne a la comunidad académica que tendrá acceso a este texto. ¿Para qué? Tengo claro que no lo hago porque piense que con

En palabras de MacKinnon (1987, p. 245): el mundo no es completamente como los que tienen poder dicen que es o quieren creer que es. Si parece serlo, es porque el poder construye la apariencia de la realidad al silenciar las voces de las personas que no tienen poder, al excluirlas del acceso al discurso de autoridad. [Traducción propia]. esto va a cambiar nuestra realidad, pero el inicio de la movilización femenina es entender la trascendencia del problema que tenemos que solucionar.

\section{Metodología}

Antes de iniciar el desarrollo de este artículo considero importante poner de presente la metodología que utilicé. Esencialmente su realización se dio a través de investigación académica de la bibliografía y la jurisprudencia relevante al respecto. De esta forma, una revisión de los principales textos escritos por Mackinnon fue fundamental para construir una concepción concreta de su argumento que, al estar dividido en premisas, pudiese traducirse en una clara herramienta para analizar los casos seleccionados.

En cuanto a la elección de la jurisprudencia han de resaltarse dos aspectos. En primer lugar, elegí casos de la Corte Constitucional puesto que son estos los que analizan hechos a la luz de la vulneración de derechos fundamentales, y en esta medida es en sede constitucional que se deben valorar las situaciones fácticas que implican una violación al derecho fundamental a la igualdad. ${ }^{7}$ Los casos tuvieron dos características en común: elegí únicamente sentencias de tutela, lo cual implica que los casos fueron seleccionados por la Corte misma para pronunciarse al respecto; a su vez, eran casos que abordaban el

7 Consideré especialmente interesante valorar jurisprudencia de la Corte Constitucional, pues esta como órgano de cierre en las discusiones que surgen en torno a la Carta Política es la máxima autoridad en interpretar los alcances de los derechos constitucionales en Colombia $\mathrm{y}$, en tal medida, sus pronunciamientos son centrales para entender el contenido que se les da a los derechos fundamentales. 
tema de cuerpos desnudos y sexualidad. Si bien hice una revisión generalizada de este tipo de jurisprudencia de la Corte, reduje mi análisis a seis casos enmarcados en los ejes temáticos ya mencionados: de medios y publicidad, educación sexual y mujeres que visitan cárceles de hombres, al considerar que en ellos Mackinnon permite iluminar aspectos realmente pertinentes.

En fin, una vez elegida la doctrina relevante para plantear el argumento de Mackinnon en tres premisas, estas fueron utilizadas como herramientas analíticas para evaluar la jurisprudencia y llevar a Mackinnon a conversar con supuestos fácticos con los que no lo había hecho antes, y así revelar aspectos de los casos que no fueron presentados en las sentencias. A continuación presentaré el producto de este ejercicio académico.

\section{EL ARGUMENTO DE CATHARINE A. MACKINNON}

\section{A. La expropiación de la sexualidad femenina}

La preocupación central de MacKinnon es la igualdad sustantiva de la mujer en la sociedad. Esta le ha sido arrebatada por el poder que el hombre ha ejercido sobre ella quitándole lo que le es más propio: su sexualidad. El funcionamiento de este poder es justificado por conceptos como consentimiento, verdad, legitimidad e incluso legalidad, y ha puesto a la mujer en una situación de inferioridad en todos los aspectos de su vida. Ha definido su realidad social, labo- ral, familiar e incluso la concepción que tiene de sí misma. ${ }^{8}$ Así, uno de los supuestos esenciales de la teoría de Mackinnon es que muchas mujeres no perciben la desigualdad del mundo en el que vivimos. ${ }^{9}$

Al abordar la importancia de la sexualidad para el feminismo, MacKinnon asegura:

Es aquel proceso que crea, organiza, expresa y dirige el deseo, creando los seres sociales que conocemos como hombres y mujeres así como sus relaciones que crean sociedad (...). Como [en el marxismo] la expropiación organizada del trabajo de algunos para el beneficio de otros define una clase -los trabajadores-, la expropiación organizada de la sexualidad de unos para el uso de otros define el sexo, la mujer. (Citada en García et al., 2006, p. 163).

Específicamente para MacKinnon, esta expropiación se entiende si vemos que no somos las mujeres quienes nos definimos a nosotras mismas, sino que:

Lo que define a una mujer como tal es lo que excita a los hombres, y les excita todo lo que es cualquier clase de mujer. Las chicas virtuosas, virginales son atractivas en lo alto de los pedestales de los que hay que bajarlas y las no

8 En este sentido, MacKinnon (1987, p. 7) sostiene que como la inequidad entre hombres y mujeres está socialmente definida como un sinónimo del disfrute de la sexualidad misma, la inequidad de sexos parece consensual.

9 Un ejemplo que permite ilustrar esta idea claramente es que, hasta hace relativamente poco, la infidelidad en Colombia era una prerrogativa masculina en el matrimonio. El artículo 154 del Código Civil establecía como causal de divorcio el adulterio de la mujer, y no fue sino hasta la Ley $1^{\circ}$ de 1976 que se cambió el texto para incluir "las relaciones sexuales extramatrimoniales de alguno de los cónyuges." 
virtuosas, las putas, son provocativas, así que se merecen lo que tienen. (1995, p. 195).

En esta medida, nos definimos según la función que nuestra sexualidad tenga para los hombres, y al ser para ellos, no es nuestra, ha sido expropiada. En concreto, Mackinnon sostiene que cada elemento del género femenino se traduce en algo sexual (citada en García et al., 2006, p. 176). De esta forma, la vulnerabilidad significa en realidad un acceso sexual fácil, pasividad significa receptividad y resistencia desactivada, y la suavidad significa permeabilidad de algo duro. La incompetencia y la vulnerabilidad de la mujer implican que esta necesita protección, lo que en últimas se convierte en una invasión a su espacio personal. Así, la sexualidad es el ámbito social primario del poder masculino (MacKinnon, citada en García et al., 2006, p. 174). No es extraño considerar entonces, que es desde el estudio de las formas en que esta se expropia, que podemos realmente empezar a emancipar a la mujer de la dominación del hombre.

\section{B. El vehículo de la expropiación de la sexualidad femenina}

La expropiación de la sexualidad de la mujer, en términos de MacKinnon, se ha dado fundamentalmente a través de las acciones. Lo anterior debe entenderse a la luz de una concepción amplia de la palabra acción, que contempla incluso lo que tradicionalmente la mayoría de las personas denominarían expresiones. Me expli$\mathrm{co}$, si bien es claro que una buena parte de los estereotipos y degradaciones de la mujer se producen a través de medios considerados como expresiones, imágenes o palabras, MacKinnon considera que estas son verdaderas acciones que más allá de decir una frase o mostrar una imagen, hacen lo que dicen o muestran (1996, p. 12). El ejemplo clásico de la autora para dar a entender esta idea es la situación de un establecimiento que pone en su puerta el letrero "sólo blancos". En este caso, podría alegarse que dicho letrero es una mera expresión. No obstante, sus efectos son una abierta discriminación que impide que personas negras entren al lugar. El letrero, más allá de decir dos palabras, es un acto de discriminación (MacKinnon, 1996, p. 13). La desigualdad de la mujer en la sociedad se ha dado a través de verdaderos actos de discriminación del hombre y no de simples expresiones.

La preponderancia que MacKinnon (1996, p. 31) da a las palabras y las imágenes es fundamental para entender su teoría:

Las palabras y las imágenes son la manera en que las personas son puestas en jerarquías, en la que la estratificación social parece inevitable y correcta, en la que los sentimientos de inferioridad y superioridad son engendrados, y cómo la indiferencia de la violencia en contra de aquellos que están abajo es racionalizada y normalizada. La supremacía social entre las personas se materializa a través de la creación de significados. Para deshacerla, estos significados y sus tecnologías tienen que deshacerse. [Traducción propia].

En concordancia con esta idea, la agenda feminista de Mackinnon se ha preocupado centralmente por el fenómeno de la pornografía. 
En este sentido, ha presentado una definición exacta de las actividades que considera se pueden definir como tal:

La subordinación gráfica sexualmente explícita de las mujeres a través de imágenes o palabras, lo que también incluye mujeres deshumanizadas como objetos sexuales, cosas o mercaderías; disfrutando del dolor, las humillaciones o la violación; siendo atadas, cortadas mutiladas, heridas o dañadas físicamente; en postura de sumisión, servilismo o exhibición sexual; reducidas a partes del cuerpo, penetradas por objetos o animales, o presentadas en escenarios de degradación, daño o tortura; mostradas como sucias o inferiores; sangrantes, heridas o lastimadas en un contexto que haga que esas condiciones parezcan sexuales. (MacKinnon, 1987, p. 176).

A su modo de ver, esta es tal vez la práctica política que más ha contribuido a construir la concepción social del género femenino, a la vez que le ha arrebatado su sexualidad. ${ }^{10}$ Aclaro, política en la medida en que el rechazo feminista a la pornografía está lejos de ser un juicio moral sobre lo que está bien y está mal, sino una preocupación de las relaciones de poder que se concretan en la industria. ${ }^{11}$ Una de las

10 En la pornografía, afirma MacKinnon (1987, p. 256), están reunidos en un mismo lugar todos los abusos en contra de los cuales las mujeres tuvimos que luchar tanto tiempo (...) la violación, los maltratos, el acoso sexual, la prostitución y el abuso sexual infantil. Solo que en la pornografía los llaman de otra manera: sexo, sexo, sexo, sexo y sexo respectivamente. [Traducción propia].

11 En su texto "La pornografía no es un asunto moral", la autora se refiere a la doctrina de la obscenidad utilizada en Estados Unidos por moralistas, como práctica política para establecer restricciones a partir de lo que está bien o mal. Según MacKinnon, representa la moral entendida desde un punto de vista masculino, viendo como bueno aquello que permite a los hombres mantenerse en el poder y como malo lo que cuestione su absolutismo. De esta forma, una perspectiva características de la pornografía que más llama la atención es que precisamente existe justificada bajo la libertad de expresión. De esta forma, MacKinnon ha analizado el contenido presentado en las películas pornográficas, para poner de presente que están compuestas por verdaderas acciones de discriminación y maltrato hacia las mujeres (1996, p. 12). Esta industria se defiende como si solo fuera una referencia de la realidad, como si solo fuesen imágenes o palabras, cuando la verdad es que, filmar a una mujer siendo amarrada y penetrada para el placer de un hombre, realmente implica hacerle esto. A su vez, es relevante considerar que estas acciones que componen la pornografía representan y expresan la posición de la mujer en la sociedad. En otras palabras, señala MacKinnon (1987, p. 257), “lo que la pornografía hace va más allá de su contenido: erotiza la jerarquía y sexualiza la desigualdad." [Traducción propia].

La pornografía interfiere en la realidad para existir, y se produce con hechos concretos, no con ideas. ${ }^{12}$ Es por el enriquecimiento de la industria pornográfica que las mujeres son convertidas en objetos sexuales que sirven al placer masculino. Es importante resaltar que en esta teoría, la

moral de la pornografía no considera que este sea un asunto de mujeres (1997, p. 52).

12 Esta situación es abordada por MacKinnon al referirse al llamado snuff porn: "Considere la pornografía snuff, en la cual mujeres o niños son asesinados para hacer una película sexual. Esto es, la filmación de un homicidio sexual mientras está siendo cometido. El homicidio es sexo para aquellos que lo hacen. El clímax es el momento de la muerte. El consumidor tiene una experiencia sexual mientras lo ve. Aquellos que matan como y para el sexo, están teniendo sexo a través del homicidio; los que ven la película están teniendo sexo a través de observar el homicidio. El porno snuff no es una discusión de la idea del homicidio sexual, como tampoco lo son los actos que están siendo grabados. La película no 'se trata de' homicidio sexual; sexualiza el homicidio.” (1996, p. 35). [Traducción propia]. 
pornografía no solo es reprochable cuando hay violencia pura en las imágenes. Incluso muchas veces imágenes o videos que subordinan a la mujer en la sociedad son confundidos con arte o expresiones publicitarias, lo cual para Mackinnon sucede "en cuanto se hace evidente, que lo degradante para la mujer es atractivo para el consumidor" (citada en García et al., 2006, p. 179). La libertad de expresión -valor liberal creado por el hombre y para el hombre-justifica la existencia de este tipo de prácticas y otras igual de degradantes pero en otros escenarios, como lo explicaré más adelante con el caso de la emisora colombiana La Mega.

Vemos entonces cómo lo que ocupa la teoría de Mackinnon es desdibujar la línea tradicional que ha diferenciado las acciones de las expresiones. La idea de la acción como una simple manifestación es cuestionada en la medida en que las acciones representan determinadas convicciones de poder, a su vez una expresión no solo pone de presente una idea, sino que llega a ser un verdadero acto de discriminación. En la pornografía esta idea se puede entender si vemos cómo las acciones que la componen terminan construyendo la realidad del género, lo cual a su vez evita que veamos los daños que produce. Iguales materializaciones de esto pueden verse en las violaciones, el acoso sexual, el acoso laboral o la prostitución, entre muchas otras formas de denigrar a la mujer, como las que mostraré en el análisis de los casos, donde se presentan supuestos de hecho en los cuales las acciones y representaciones son las que demuestran y realizan la subordinación del sexo femenino en la sociedad.

\section{La subordinación de la mujer}

La tercera parte del argumento de MacKinnon se refiere a los efectos de lo que he explicado hasta ahora: el silenciamiento social de la mujer, que en últimas, es la muestra de su subordinación en la sociedad. La expropiación de la sexualidad femenina es, a la vez, la expropiación de su voz, la cual se puede ver materializada de dos formas: a) cuando las mujeres recurren al silencio real y no hablan acerca de su subordinación, ni mucho menos hacen algo para cambiar su realidad; o, b) por el contrario, cuando a pesar de que intentan hablar y denunciar lo que les está pasando, no son escuchadas, pues se consideran objetos sexuales que no tienen credibilidad.

Para dar a entender esto, MacKinnon Ilega hasta el punto de decir que la libertad de expresión como valor liberal no le pertenece a la mujer. “El liberalismo nunca ha entendido que la libre expresión es de los hombres y silencia la libre expresión de las mujeres (...) lo cual es difícil de demostrar porque el silencio no es elocuente" (MacKinnon, 1997, p. 61). En su libro Feminism Unmodified, cuestiona cómo la mujer se ve beneficiada por los propósitos de la libertad de expresión con una práctica que existe bajo ese rótulo, como la pornografía. Niega que al género femenino se le permita la autorrealización individual, la facilidad del consenso, la participación en la vida cívica o la facilitación del cambio a través de una industria como la pornográfica. De esta forma, al no poder acceder a los propósitos del derecho, este no nos pertenece. 
Finalmente, a pesar de que MacKinnon considera que la libertad de expresión es un valor liberal masculino, incluye dentro de su agenda la necesidad urgente de la intervención estatal para lograr un acceso a la expresión que siempre nos ha sido negada. E incluso sostiene que un sistema que pretenda solucionar el problema del silenciamiento social femenino, sería uno serio respecto de la garantía de este derecho (1987, p. 304).

\section{D. ¿Qué pasa cuando esto le sucede a los hombres?}

Antes de entrar a utilizar los argumentos recién estudiados como herramienta metodológica, encuentro importante abordar la respuesta a varias preguntas que sin duda surgen leyendo a MacKinnon. ¿Qué sucede cuando esto le pasa a los hombres? En otras palabras: ¿Qué pasa cuando son solo hombres los involucrados en la pornografía, o cuando son acosados sexualmente, o utilizados como objetos sexuales? ¿No sería esto lo mismo que le ocurre a las mujeres? y en esa medida, ¿No perdería sentido el argumento de que este es un problema que concierne al feminismo? Mackinnon presenta una visión muy concreta frente a todos estos cuestionamientos, y en esencia considera que hacerse estas preguntas hace parte de la necesidad de restablecer la falsa igualdad en la que queremos creer. $^{13}$

13 En el mismo sentido, MacKinnon considera que esto de "a los hombres también", significa que la gente en realidad no cree todas las estadísticas de mujeres cosificadas que ella presenta, a pesar de su exactitud empírica (1987, p. 171).
Específicamente, lo que la autora considera es que existe un afán del género masculino por reafirmar la simetría y presentar los problemas más reiterativos del género femenino como problemas de los hombres también. Así, MacKinnon advierte, "si las mujeres somos lastimadas, los hombres son lastimados, si somos violadas son violados, si las mujeres somos acosadas sexualmente los hombres también lo son, si las mujeres sufrimos maltrato físico los hombres sufren maltrato físico" (1987, p. 170). [Traducción propia]. Sin embargo, existe una gran diferencia, y es que estas situaciones no definen a los hombres socialmente. En esta medida, si bien es cierto que hay casos en los cuales el hombre se ve involucrado pasivamente en la pornografía, el acoso sexual y la cosificación, estos no definen el estatus del grupo social de los hombres como inferior, como sí lo hacen con el de la mujer.

\section{LA SEXUALIDAD FEMENINA EN LA JURISPRUDENCIA DE LA CORTE CONSTITUCIONAL COLOMBIANA}

Habiendo estudiado las ideas de MacKinnon, en esta sección me dedicaré a utilizarlas como herramienta metodológica, analizando casos de jurisprudencia constitucional colombiana sobre cuerpo y sexualidad. A pesar de que este no es un tema reiterativo para la Corte Constitucional, existe suficiente material para poner de presente que es poca la atención que se está prestando en sede constitucional a la discriminación de género por expropiación de la sexualidad. Para abordar en detalle la jurisprudencia, dividiré 
esta sección en tres, según el tema a tratar. En primer lugar abordaré el tema de la mujer en los medios y la publicidad, luego hablaré sobre la educación sexual y finalmente de las mujeres que visitan las cárceles de hombres.

Es importante aclarar que este análisis no pretende plantear que existe un propósito malicioso por parte de la Corte Constitucional de excluir los debates de discriminación de género de sus sentencias, sino que parto del supuesto de que ellos también viven en la falsa conciencia propuesta por Mackinnon.

\section{A. Medios y publicidad}

En toda su trayectoria, solo ha habido una sentencia en que la Corte Constitucional se ha pronunciado frente a los derechos de la mujer cuando se trata de publicidad. Pero no en términos de las implicaciones para la igualdad que esta tiene en sí misma como imágenes o expresiones, sino por los efectos indeseados que pueda llegar a producir, por ejemplo incitando a la violencia (CConst., T-722 de 2003, Á. Tafur). Este fue el caso de una publicidad institucional del Programa de Atención al Desmovilizado del Ejército Nacional, compuesto por más de dos millones de calendarios con la foto de una mujer en vestido de baño y un texto que decía "'iVuÉLESE ya! y obtenga beneficios jurídicos, económicos, salud, educación y lo más importante su LIBERTAD". La tutela fue promovida por Magdala Velázquez Toro, Patricia Buriticá, María Ximena Castilla Jiménez, María del Rosario García, Luz Sánchez, Jaime Santamaría Pombo y Patricia Gallego; además anexaron a la demanda 80 firmas apo- yando la tutela en contra de la publicidad mencionada, alegando la vulneración de derechos fundamentales a la vida, dignidad e integridad física y sicológica de las mujeres.

La Sala, al responder a la preocupación de los accionantes de que la imagen pudiese llegar a generar más violencia en contra de la mujer en el contexto del conflicto armado colombiano, afirmó:

El Estado tiene el deber de librar [a la mujer] de la violencia, de manera específica, la Constitución proscribe toda discriminación contra la mujer y ordena la realización de la igualdad de derechos y oportunidades entre hombre y mujer (...) así las cosas, no sobra advertir que la representación de un mensaje publicitario no puede instrumentalizar al individuo en razón del género, pues desconocería el principio de dignidad humana en el que se funda el Estado y constituiría una de las formas de violencia en su contra. (CConst., T-722 de 2003, Á. Tafur, p. 17).

Si bien esta afirmación parece suponer una ganancia para los derechos de la mujer, además de ser la única en el caso y reafirmar el supuesto de igualdad entre hombres y mujeres contenido en la Constitución Política, al no dirigirse explícitamente a la vulneración de la igualdad sino abordar la situación desde una perspectiva de dignidad humana, no profundiza en la cosificación sexual que propiciaron los calendarios como tal. Lo anterior no permite valorar que estos fueron concretamente la fuente de la desigualdad y de la expropiación de la sexualidad. Otra manifestación de la Corte que es del caso 
resaltar es cómo esta se abstrae por completo de un análisis concreto de la pieza publicitaria, al afirmar: "No corresponde a esta Sala entrar a definir si las imágenes impresas en los calendarios de bolsillo pueden ser calificadas de insinuantes o pornográficas" (CConst., T-722 de 2003, Á. Tafur, p. 15). En seguida, la Sala se limita a hacer un llamado de prevención a las entidades públicas para que su publicidad incorpore los valores constitucionales inherentes a su misión institucional. Sin embargo, este es un llamado generalizado y a mi modo de ver vacío, por lo cual el pronunciamiento constitucional se queda corto en determinar las verdaderas implicaciones que acarrearon los supuestos del caso.

Estudiar estos hechos a la luz de MacKinnon permite ver que, más allá de los efectos que llegaran a producir los calendarios (que sin duda es una discusión relevante), estos representaron una expropiación de la sexualidad femenina a través de las imágenes y las palabras. De entrada, se debe afirmar que existió una expropiación en la medida en que plantear que la mujer es sinónimo de libertad para el hombre, es suponer que la mujer no es un sujeto que puede decidir acerca de su sexualidad. De hecho, es asumir que la mujer es un objeto, más precisamente, el trofeo que recibirían los guerrilleros al desmovilizarse. En este caso, la imagen y las palabras utilizadas en los calendarios fueron el medio para convertir a la mujer en un objeto. Especialmente, llama la atención que se haya elegido poner una foto de una mujer en un vestido de baño de dos piezas, pues sin duda en ella se sexualiza aún más, con toda la atención puesta sobre su cuerpo y sus atributos físicos. También es del caso hacer un análisis detenido de la elección de palabras hecha para la campaña. La palabra libertad, que se concibe como el principal beneficio de la desmovilización, se Ilena de contenido con la imagen que acompaña la frase. En este sentido, la libertad de un hombre existe mientras pueda ejercerla sobre algo, que en este caso es la mujer.

La jerarquía entre sexos que esta pieza de publicidad construye y legitima en sí, sin duda conlleva al silenciamiento social. Presupone que la mujer es un objeto sexual, sin libertad propia, que el hombre utiliza para poder ejercer "lo más importante, SU libertad". A la vez, esta pierde su voz, porque los objetos no hablan (Mackinnon, 1987, p. 275). En esta medida, vemos cómo más allá de los efectos de los calendarios en un contexto de conflicto, que fue el eje central de discusión en la sentencia de la Corte, en cualquier contexto esta publicidad, en sí, expropia a la mujer de su sexualidad, subordinándola en la sociedad. Por demás, esta pieza pareciera partir de una suposición del Programa para Desmovilizados del Ejército, muy interesante, y es que solo existen combatientes hombres o que las mujeres que están en la guerrilla son todas lesbianas (CConst., T-722 de 2003, Á. Tafur, p. 4). Esto, retomando que el incentivo que se propone para la desmovilización es la posibilidad de poder acceder al cuerpo de una mujer para materializar su libertad.

Dentro de este mismo eje temático encontramos el caso del programa de radio El Mañanero de La Mega (CConst., T-391 de 2007, M. 
J. Cepeda), el cual considero un caso hito que muchas veces es utilizado para entender el contenido que el derecho a la libertad de expresión tiene en Colombia. Inicia con una acción popular interpuesta en el 2003 por la Fundación Un Sueño por Colombia, en contra del Ministerio de Comunicaciones y Radio Cadena Nacional S. A. (RCN), por considerar que la moral pública, las buenas costumbres, los valores, la integridad física y psíquica de la sociedad, y derechos colectivos como el patrimonio público, el patrimonio cultural, la seguridad y salubridad pública y los derechos de los consumidores y usuarios de radio en Colombia estaban siendo vulnerados por la transmisión del programa radial "El Mañanero de La Mega". La violación de tales derechos se origina según el accionante por el contenido sexual y vulgar abordado. Esta acción popular prosperó en primera instancia ante el Tribunal Administrativo de Cundinamarca, y fue confirmada por el Consejo de Estado. No obstante, RCN interpuso una acción de tutela en contra de la providencia de segunda instancia, por considerar que esta constituía una vía de hecho, especialmente por vulnerar su derecho a la libertad de expresión. ${ }^{14}$ La tutela fue concedida por la Corte Constitucional.

14 En criterio del accionante, tanto la parte motiva como la parte resolutiva de la sentencia proferida por el Consejo de Estado constituyen una vía de hecho. Para sustentar esta aseveración, el demandante divide en dos los argumentos pertinentes. En un primer capítulo presenta las circunstancias de hecho y de derecho que en su criterio constituyen una violación de los derechos fundamentales. En el segundo explica por qué en este caso están dadas las condiciones para que se haya configurado una vía de hecho, en especial por violación del derecho fundamental a la libertad de expresión, ya que las providencias judiciales y la resolución ministerial constituyen, a su juicio, censura. También estima violado su derecho a la igualdad, porque otras emisoras con programas semejantes no han sido sancionadas, alega que la sentencia incurrió también en un defecto fáctico.
Esta sentencia es especialmente interesante, porque a pesar de que los hechos son abrumadoramente denigrantes para la mujer -como lo presentaré enseguida- su rol pasa desapercibido. En primer lugar, la acción popular se basó en la moralidad para rechazar el contenido del programa. Desde el feminismo radical es fundamental reiterar que la moralidad no es un argumento para intentar reclamar los derechos de la mujer, precisamente porque, como en este caso, no se preocupa por su igualdad, sino por lo que considera que está bien o mal. A su vez, el problema jurídico propuesto por la Corte se enmarcó en la dicotomía libertad de expresión y derechos de las niñas, niños y adolescentes de la audiencia, a no ser expuestos a contenido sexual explícito. En más de 250 páginas que componen la sentencia, no se encuentra alguna preocupación por la degradación para la mujer que llegaron a constituir las expresiones utilizadas en el programa radial. La Corte se concentra en poner de presente que la censura en Colombia está proscrita, y la libertad de expresión es un derecho inamovible para la democracia. Así, el mismo argumento que ha acompañado la existencia de la pornografía durante años, en este caso acompaña las expresiones degradantes hacia la mujer en la radio. Específicamente las expresiones utilizadas por los dos locutores hombres, incluían:

... La virginidad después de los 15 es un desaseo, cochinas, mano de cochinas... la primera que muestre que está con hilo dental..., la primera que le tire un brasier a Mauricio en la cara se gana las boletas... yo les voy a enseñar a todos, uno coge la vieja y la mira y le dice: 
mechas, mechas, la vieja que? mechas una mamadita... yo soy amante del porno, amante total, me declaro amante furibundo del porno, es mi única, es mi única afición. (CConst., T-391 de 2007, M. J. Cepeda, p. 92). [Puntos suspensivos en el original].

Con una lectura rápida de estas frases, es más que obvio que cada una de ellas se compone de dos temas, sexo y mujeres. Ejercen una expropiación de la sexualidad tal, que aquellas que a sus quince años no hayan querido tener sexo son calificadas como "cochinas", lo cual reitera la obligación femenina de participar en el sexo para ser aceptadas y tener un lugar, así sea subordinado, en la sociedad. Las que exploten su sexualidad, mostrando la ropa interior, o tirando un brasier, reciben incentivos como ganar boletas, lo cual en realidad es un premio por alimentar el placer de los locutores. El sexo oral que el hombre recibe de la mujer, es concebido a la vez como un chiste y una orden que todos los hombres deberían aprender a dar. Y la pornografía, fuente central de degradación de la mujer para Mackinnon, recibe un aplauso y se caracteriza como una afición, como si fuera un deporte. Igual de interesante es ver cómo este es un programa cuya audiencia está compuesta en su mayoría por niños, niñas y adolescentes, afectando desde temprano la construcción social de la concepción que las mujeres tienen de sí mismas, y los derechos que los hombres se van a otorgar sobre la sexualidad femenina.

En cuanto al medio utilizado, nuevamente vemos el protagonismo de la libertad de expresión, esta vez a través de un programa radial.
Concretamente se puede ver cómo las palabras utilizadas para referirse a la mujer en el programa contribuyen a construir el imaginario social del género femenino como la fuente obligada de placer para los hombres. La consecuencia de estas acciones de discriminación, es la desigualdad de la mujer como sinónimo de sexo en la sociedad, que no tiene credibilidad, incluso desde su niñez. En términos de MacKinnon, el silenciamiento social femenino.

En fin, la jurisprudencia de la Corte Constitucional que se presta para hablar de la expropiación de la sexualidad de la mujer en medios y publicidad, es suficientemente ilustrativa para decir que aunque los hechos que han llegado a revisión de tutela justifican una discusión acerca de la discriminación de la mujer a través de las expresiones, esta no se ha dado.

\section{B. Educación sexual}

Pasaré ahora a abordar la jurisprudencia de la Corte que considero pertinente para el ejercicio que he venido haciendo, en el tema de educación sexual. Si bien dentro de este tema ha habido casos que involucran el género masculino y femenino, discutiré dos que vistos desde los argumentos de Mackinnon han significado una afectación al derecho a la igualdad de las mujeres.

El primero de estos sucedió en el año 2004 (CConst., T-220 de 2004 E. Montealegre), cuando una ciudadana ${ }^{15}$ interpuso una acción de

15 El nombre es reservado por la Corte por estar involucrada una menor de edad. 
tutela en nombre de su hija de 14 años, al considerar que una funcionaria del establecimiento educativo en el que estudiaba había vulnerado los derechos de la niña a la dignidad, el buen nombre y la honra. La docente, expresó frente a todo el colegio:

Las alumnas mujeres se [deben dar a] respetar de los mismos compañeros, me da tristeza, que muchos ya parecen unas guitarras, todo el mundo los toca; (...) a veces encontramos jóvenes que directamente les cogen la cola y con qué autoridad piden respeto si ya han permitido anteriormente hacerlo? (...) quisiera saber qué pasa con una niña llamada (...) de la cual se tienen comentarios de los mismos compañeros, (...), así si las niñas no se dan a respetar tránquenlas y enséñenles que después le (sic) pueden faltar al respeto y que eso no lo quieren hacer. (CConst., T-220 de 2004, E. Montealegre, p. 6).

La discusión constitucional que acompañó la mencionada tutela consistió en preguntarse por los alcances de la labor de la docente, para garantizar valores como el respeto y la disciplina. A su vez, la Sala se preguntó si la censura pública del comportamiento de la estudiante constituía una conducta violatoria del derecho a la educación. A pesar de que la Corte sí aborda la importancia de la sexualidad en esta sentencia, e incluso llega hasta calificarla como una "dimensión integral de la existencia humana", la discusión se ciñó únicamente a las implicaciones de la sexualidad en la educación escolar, y no fue llevada hasta valorar las implicaciones que la expropiación de la sexualidad de la menor a través de las expresiones de la docente tuvie- ron para la igualdad de género. Miraré ahora por qué este sí fue el caso.

Retomando las palabras expresadas por la profesora, no cabe duda de que trascienden el concepto de expresión para convertirse en acciones que discriminaron a la menor. ${ }^{16}$ En síntesis, lo que la profesora expresa es que la actividad sexual entre las y los estudiantes surgió por culpa de las niñas que no se dan a respetar. Peor aún, en su discurso llega hasta afirmar que por haber tenido algún contacto sexual, estas menores no podrán hacerse respetar en el futuro. Afirmó implícitamente que no son dueñas de su sexualidad, y al utilizarla con un estudiante la están dejando a su disposición permanente. Así, cuando la profesora expresa "cómo piden respeto si ya [le] han permitido anteriormente hacerlo" contribuye a la construcción de una imagen de la mujer donde esta no es dueña de su sexualidad y sus decisiones. En términos prácticos, la consecuencia de esto es que después de dar consentimiento la primera vez, la mujer no tiene voz para determinar cómo quiere vivir su vida sexual. En pocas palabras, la docente utilizó su autoridad en la institución, y expresó ideas que no solo expropian a la mujer de su sexualidad sino que restan cualquier tipo de valor que su voz pueda llegar a tener, silenciando a la mujer. Es claro que los hechos del caso fueron mucho más que una simple situación de lineamientos de educación sexual.

16 Es interesante cómo en las expresiones de la docente, siendo mujer, también se puede valorar la existencia de una falsa conciencia, en la medida en que esta está convencida de ideas que en esencia favorecen la posición de superioridad del hombre en la sociedad. 
Otro caso de discriminación que vale la pena analizar sucedió en el año 2005 (CConst., T-864 de 2005, Á. Tafur), cuando la madre de una niña que cursaba sexto grado en el colegio, interpuso una acción de tutela en contra del Secretario de Educación Municipal. ${ }^{17}$ Esto, al considerar que se violaron los derechos de su hija a la educación, la integridad moral y a no recibir tratos degradantes, por "la conducta inmoral y contraria a la ética por parte de un docente y por la conducta omisiva del funcionario accionado." Concretamente, la madre relató cómo su hija expresó que un profesor del colegio le mandó la mano a tocarle la vagina, pero que ella logró voltear un poco, alcanzándole a tocar en una nalga y que a raíz de eso, en el salón se destaparon muchas compañeras a contar cómo a ellas también les ha tocado los senos (CConst., T-864 de 2005, Á. Tafur, p. 3).

Luego de esto, se entregaron quejas por escrito al rector del Colegio e incluso a la Personería Municipal, sin embargo, no cambiaron el profesor, alegando que no se podía vulnerar su derecho al debido proceso. Cuando las niñas ingresaron nuevamente a sus clases, este les dijo que con él iban perdiendo el año.

La Corte enmarcó los hechos en una discusión jurídica de educación sexual para la comunidad educativa, el interés superior del niño y la competencia de las autoridades municipales frente a los docentes escalafonados. En ningún momento se dirigió a las implicaciones que el abuso sexual tiene para las relaciones de poder

17 Nuevamente, por ser un caso que involucra menores de edad los datos exactos no son revelados. que enfrentan estas niñas en la sociedad, como a continuación explicaré.

Estos hechos, ya no se tratan de una situación en la cual las acciones de discriminación se esconden en expresiones. Este es un caso en que la acción misma realiza la expropiación de la sexualidad femenina, subordinando a la mujer en todos los aspectos de su vida. Aquí, un hombre ejerce el poder que tiene sobre el género femenino, abusando de su posición de superioridad y arrebatando a las niñas su sexualidad. Utilizó el cuerpo de las menores para satisfacer su placer sexual, materializando la idea de que las mujeres existimos para eso. Además, cuando las niñas denunciaron la situación, el docente a manera de amenaza les expresó que con él iban perdiendo el año, negándoles la posibilidad de expresar su inconformidad libremente, silenciándolas. El abuso sexual de las menores contribuye al estereotipo arraigado en la sociedad de que el hombre puede utilizar a la mujer. Puede obtener su placer, cuando quiera y como quiera - con o sin consentimiento-, considera a la mujer como un objeto para el sexo, y en esa medida, está subordinada a su deseo. A su vez, hay otro elemento de este caso que contribuye al silenciamiento femenino y es la preponderancia que se da al debido proceso del docente frente a la voz de las niñas que denunciaron el abuso sexual. Esta es una muestra clara de la poca credibilidad que las mujeres podemos llegar a tener en la sociedad, donde podemos hablar pero no se nos escucha.

Quise poner de presente con estos casos que en el marco de la educación sexual en Colombia, 
sin duda se han presentado hechos que suponen una subordinación del género femenino. De estos, como lo hice con el primer eje temático, también puedo concluir que la Corte no abordó temas de igualdad a pesar de que los supuestos fácticos lo ameritaban. Esta situación se repetirá en los casos que trataré enseguida.

\section{Las mujeres que visitan cárceles de hombres}

Las situaciones que viven las mujeres que ingresan como visitantes a los centros penitenciarios masculinos en Colombia han sido ampliamente discutidas en la jurisprudencia constitucional. Probablemente esto se debe a la reiteración de abusos en estos escenarios. Para el análisis al que concierne este escrito, considerando que son varias sentencias las separé en dos subtemas. El primero, será en general sobre las requisas degradantes que realizan a estas mujeres, luego hablaré específicamente sobre la imposibilidad del ingreso de mujeres que tienen la menstruación, como visitantes a la cárcel.

Para entender las implicaciones en el tema de desigualdad de género, que surgen alrededor de estos hechos, es preciso hacer una contextualización de la forma en que sucedieron, que básicamente es reiterativa en las tutelas que se han interpuesto al respecto. ${ }^{18}$ Cuando las mujeres visitaban centros penitenciarios masculinos, guardias del Instituto Nacional Penitenciario (INPEC) -también mujeres- les realizaban requisas

18 Corte Constitucional, sentencias T-501 de 1995, V. Naranjo; T-269 de 2002, M. G. Monroy; T-690 de 2004, Á. Tafur. denigrantes, incluyendo pero no limitándose a desnudarlas, obligarlas a mostrar los senos, tomar posiciones como cuclillas o flexiones de rodillas, y permitir tactos vaginales, sin siquiera haber un cambio de guante, aduciendo que escondían algún elemento ilegal. Lo anterior sucedía a pesar de que los centros contaban con aparatos de detección de metales y perros detectores de explosivos o narcóticos. A su vez, es común encontrar en los casos estudiados, que a pesar de que las mujeres se quejaban respecto de los ultrajes que se realizaban en las requisas, se las amenazaba con no dejarlas volver a entrar si se negaban a recibir tales tratos (CConst., T-690 de 2004, Á. Tafur, p. 3).

Las tutelas que se han presentado frente a este tipo de situaciones han sido promovidas alegando que constituyen una vulneración a los derechos de las visitantes a la dignidad, libre desarrollo de la personalidad, y a no ser sometidas a tratos crueles, inhumanos y degradantes. Por su parte, la Corte Constitucional siempre ha tutelado los derechos mencionados considerando este tipo de requisas, a todas luces, inconstitucional, pero ha enmarcado la situación en un contexto de dignidad humana y no de género, como propondré enseguida.

Una de las principales cuestiones que surge para justificar no considerar este caso un problema de género, es el hecho de que también ha sucedido que a los hombres les realicen requisas degradantes, incluyendo tactos anales, y la adopción de posiciones humillantes. Precisamente aquí resulta relevante retomar lo mencionado al inicio de este artículo acerca de la 
idea de que "a los hombres también les pasa". La diferencia, como ya lo mencionaba, está en que este tipo de situación de expropiación sexual define a la mujer en la sociedad, esto es, construye el significado de lo que es ser mujer. Completamente diferente en el caso de los hombres, quienes a pesar de estar involucrados en este tipo de hechos continúan teniendo en la sociedad el poder que luego ejercen sobre las mujeres. En otras palabras, estas situaciones debilitan a la mujer como grupo social y la mantienen en la posición de inferioridad histórica que siempre ha tenido, mientras que para el hombre estos acontecimientos no definen su género ni posición social.

En cuanto al análisis concreto de los hechos, tenemos una acción que más allá de realizarse por una mujer sobre otra, se ejecuta por una guardia del INPEC que representa al Estado, el cual en términos de Mackinnon, en realidad es la materialización de los ideales masculinos, y fue creado por y para el hombre. ${ }^{19}$ Así, la expropiación de la sexualidad de la mujer se ve en cada una de las actuaciones de estas guardias sobre las visitantes, a través de la desnudez obligada, anulando por completo su posibilidad de objetar, con el tacto vaginal que por demás se hacía con el mismo guante para varias mujeres exponiéndolas a enfermedades de transmisión sexual y desatendiendo por completo su dere-

19 "El Estado es masculino en el sentido feminista. La ley ve y trata a las mujeres como los hombres ven y tratan a las mujeres. El Estado liberal constituye con coacción y autoridad el orden social a favor de los hombres como género, legitimando normas, formas, la relación con la sociedad y sus políticas básicas. Las normas formales del Estado recapitulan el punto de vista masculino en el nivel de designio." [Traducción propia]. (MacKinnon, 1989). cho a la salud, así como la adopción de posiciones degradantes. En fin, la cosificación de la mujer en un nivel desmesurado, para permitirle el ingreso a visitar un hombre en una cárcel.

Incluso, yendo más allá y pensando en la razón por la cual la mujer está siendo requisada, la expropiación de su sexualidad resulta aún más clara. La justificación de los centros penitenciarios para realizar la requisa es que innumerables veces han encontrado armas blancas, drogas y explosivos, entre otras cosas, que las mujeres intentan ingresar al penal en sus vaginas. Extraña que frente a esta situación el Estado no se pregunte por qué llegaron esos objetos ahí, sino más bien, ¿cómo los vamos a sacar? Visto en los términos más escuetos posibles, las mujeres están siendo utilizadas como medios de transporte para ingresar elementos ilegales a las cárceles, que sus parejas, hermanos, amigos, etc., probablemente les han pedido. Vemos entonces cómo en realidad la cosificación es doble. Primero, porque la mujer es utilizada como un medio de carga para entrar a la cárcel elementos que los hombres necesitan; y segundo, porque es requisada desatendiendo cualquier afectación a su sexualidad que pueda estar implicada, como si esta no le perteneciera y fuese un objeto. Como ya lo he puesto de presente, la cosificación es sinónimo del silenciamiento social. La prueba de esto, en el caso concreto, es que la respuesta a las quejas por los tratos degradantes fue que si no estaban de acuerdo no podían realizar la visita.

Una aclaración final es necesaria: si bien es cierto que las requisas degradantes y la utiliza- 
ción de las mujeres como medio de transporte de elementos ilícitos hacia las cárceles suponen una doble subordinación, también lo es que las requisas a la entrada de los centros penitenciarios resultan necesarias como medio para evitar que, en efecto, se ingresen dichos objetos. En alguna medida son un mecanismo de control frente al uso de las mujeres como un medio de transporte. El punto entonces no es que las requisas no deban existir en su totalidad, sino que estas se realicen dentro de unos límites razonables que no denigren a la mujer y la expropien de su sexualidad, como por ejemplo utilizando debidamente sillas detectoras de metales, o perros antinarcóticos.

La desigualdad de la mujer se puede observar con mayor claridad, e incluso es abordada por la Corte Constitucional, en los casos en que se ha impedido el ingreso de las mujeres a los centros penitenciarios por tener la menstruación. Justificadas por la dificultad que la menstruación implica para realizar tactos vaginales, o la posibilidad de que las mujeres Ileven objetos dentro de las toallas higiénicas, diferentes cárceles del país han impedido el ingreso de mujeres con estas excusas (CConst., T-848 de 2005, M. J. Cepeda; T-622 de 2005, Á. Tafur).

Los reclamos que las mujeres han hecho en casos como estos han sido por vulneraciones a la dignidad humana, la intimidad personal y la igualdad. A su vez, todas las decisiones tomadas por la Corte al respecto han sido concediendo la tutela de estos derechos. En esta medida, es relevante resaltar que de todos los casos estudiados hasta ahora, este ha sido el único caso de expropiación de la sexualidad femenina en el cual la Corte Constitucional tutela el derecho a la igualdad de las mujeres. No obstante, a mi modo de ver, la tutela de dicho derecho no es suficiente cuando la discusión propiciada no se enmarca como una problemática de género sino de dignidad humana, como también sucedió con las anteriores sentencias recién estudiadas. En seguida explicaré más a fondo esta idea.

Una revisión juiciosa del análisis de la Corte permite ver cómo, para cada una de las tutelas interpuestas, se incluyó al menos una afirmación de plano diciendo que la discriminación de la mujer durante su periodo menstrual es una acción lesiva de la dignidad humana. Dicha afirmación contiene dos elementos. El primero: en efecto los hechos constituyen una discriminación hacia la mujer, esto es, una vulneración a su derecho a la igualdad; y el segundo, que esto conlleva a la vulneración de la dignidad humana. No obstante, también es del caso aclarar que la Corte no se extendió en las implicaciones de fondo que surgen con esta discriminación para el género femenino. Esto precisamente es lo que un análisis a la luz de MacKinnon permitirá hacer.

Antes de retomar nuevamente en detalle los hechos, considero del caso reiterar que a MacKinnon lo que le preocupa fundamentalmente es la subordinación de la mujer en la sociedad. En esta medida, más que preguntarse por las diferencias entre hombres y mujeres, que claramente existen, la cuestión es cómo estas diferencias están siendo utilizadas para determinar una ecuación de poder donde la mujer sale 
perdiendo. Entonces, lo que resulta interesante en este caso es evaluar cómo un hecho de la naturaleza biológica de la mujer, como es la menstruación, que además hace parte de su sexualidad, se utiliza como una herramienta para ponerla en una situación de inferioridad y hacerle prohibiciones.

Visto desde los hechos concretos del caso, el Estado, que como ya había establecido es una construcción masculina, decide unilateralmente prohibir el ingreso de las mujeres a los centros penitenciarios por tener la menstruación, aduciendo que dificulta la labor de requisa. Es evidente la actitud selectiva que existe. A pesar de que la menstruación también es un elemento íntegro de nuestra sexualidad, al resultar incómodo o engorroso para los fines del INPEC, la mujer ya no es utilizada como objeto, sino desechada como objeto. Por último, este caso también permite evaluar los alcances del poder de subordinación que el hombre tiene sobre la mujer; es un caso especial de silenciamiento social, donde la mujer no solo no puede hablar, y decir que está en desacuerdo, sino que por ser mujer, con todos los elementos biológicos que esto implica, incluyendo tener la menstruación, no puede actuar e ingresar como visitante al centro de reclusión.

\section{CONCLUSIONES}

Como lo mencioné al inicio de este texto, mi primera intención fue utilizar las ideas feministas de Catharine Mackinnon como herramienta metodológica para analizar jurisprudencia de la Corte Constitucional colombiana. A su vez quise llevar a MacKinnon a conversar con supuestos fácticos con los que no lo había hecho antes. Para cumplir con este propósito propuse una comprensión de las ideas de la autora a partir de tres premisas: las mujeres somos expropiadas de nuestra sexualidad por los hombres, esto se realiza a través de acciones, y la consecuencia es la subordinación generalizada del sexo femenino. Habiendo establecido y explicado estos tres argumentos, los utilicé para iluminar aspectos de jurisprudencia sobre cuerpo y sexualidad femenina que no fueron analizados por la Corte Constitucional en las sentencias seleccionadas. En este estudio de jurisprudencia determiné dentro de los ejes temáticos de medios y publicidad, educación sexual, y visitas de mujeres a cárceles de hombres, por qué los supuestos fácticos en efecto ameritaban un análisis desde una perspectiva de la subordinación del sexo femenino.

De entrada también había determinado que mi segundo propósito era elevar la conciencia de quien lea este texto frente a la situación de la sexualidad femenina en el constitucionalismo colombiano. Esto lo quise hacer revelando aspectos de casos que si bien ya han sido estudiados por la Corte, como ya lo he venido diciendo, no evaluaron aspectos en mi opinión muy relevantes para identificar la situación de subordinación de la mujer. Estos descubrimientos fueron una forma de presentar lo normalizado que está en la sociedad expropiar a la mujer de su sexualidad, y lo lejos que estamos de alcanzar la equidad tan prometida.

El feminismo radical revoluciona lo que conocemos como la realidad. Aplicar las ideas de Mac- 
Kinnon a hechos concretos puede significar el primer paso para entender que esa supuesta igualdad no es más que eso, un supuesto, no una realidad.

\section{Referencias}

1. Corte Constitucional de Colombia. Sentencia T-501 de 1995 (M. P.: Fabio Morón Díaz; noviembre 8 de 1995).

2. Corte Constitucional de Colombia. Sentencia T-269 de 2002 (M. P.: Marco Gerardo Monroy Cabra; abril 18 de 2002).

3. Corte Constitucional de Colombia. Sentencia T-722 de 2003 (M. P.: Álvaro Tafur Galvis; agosto 20 de 2003).

4. Corte Constitucional de Colombia. Sentencia T-690 de 2004 (M. P.: Álvaro Tafur Galvis; julio 22 de 2004).

5. Corte Constitucional de Colombia. Sentencia T-220 de 2005 (M. P.: Marco Gerardo Monroy Cabra; marzo 10 de 2005).

6. Corte Constitucional de Colombia. Sentencia T-622 de 2005 (M. P.: Álvaro Tafur Galvis; junio 16 de 2005).

7. Corte Constitucional de Colombia. Sentencia T-848 de 2005 (M. P.: Manuel José Cepeda Espinosa; agosto 16 de 2005).
8. Corte Constitucional de Colombia. Sentencia T-864 de 2005 (M. P.: Álvaro Tafur Galvis; agosto 18 de 2005).

9. Corte Constitucional de Colombia. Sentencia T-391 de 2007 (M. P.: Manuel José Cepeda Espinosa; mayo 22 de 2007).

10. García, M.; Jaramillo, I. C. y Restrepo, E. (2006). Crítica jurídica: teoría y sociología jurídica en los Estados Unidos. Bogotá D. C.: Ediciones Uniandes.

11. Mackinnon, C. A. (1987). Feminism unmodified: discourses on life and law. Cambridge, Massachusetts: Harvard University Press.

12. MacKinnon, C. A. (1989). Towards a Feminist Theory of the State. Cambridge, Massachusetts: Harvard University Press.

13. Mackinnon, C. A. (1995). Hacia una teoría feminista del Estado. (Martín, E., Trad.). Madrid: Ediciones Cátedra.

14. MacKinnon, C. A. (1996). Only words. Cambridge, Massachusetts: Harvard University Press.

15. MacKinnon, C. A. (1997). La pornografía no es un asunto moral. En C. Mackinnon y R. Posner, Derecho y pornografía, (Jaramillo, I. C., Trad.). Bogotá D. C.: Siglo del Hombre Editores. 